\title{
The Summary of Integrated Training Based on Information System
}

\author{
Guoxing Zhang ${ }^{1,2}$, , Weichang Zhao ${ }^{1}$, Ping Gu ${ }^{1}$, Xiaowei Chang ${ }^{2}$ \\ ${ }^{1}$ School of Ordnance Engineering College, Shijiazhuang 050003, China. \\ ${ }^{2} 69223$ Force, Xinjiang Baicheng 842300, China. \\ ag77662887@qq.com.
}

Keywords: information system, integrated training, digital troops.

\begin{abstract}
Based on the background, exploration of practice and direction of development of the integration training mode of information system , according to the main content and integrated training hierarchy of the US Army's digital troops integrated construction, this paper analyses the typical characteristics and experiences of the integrated training of the US Army's digital troops and puts forward the enlightenment and suggestions on the integrated training of information system based on the basic platform, network support, theoretical basis, methods and means, and security conditions.
\end{abstract}

\section{Introduction}

To generate the combat capability based on information system, the new training mode and methods must be created based on information weapon equipment and information systems, which is integrated training. From the pilot of integrated training of combat elements and synthesis training of combat unit, gradually promote the training mode innovation under the condition of information, a new model is developed with the current practical training: Based on information system integration, and its essence is the use of the integration method based on command information system, to carry on overall training for combat units, combat elements and combat system, the ultimate aim is to develop the combat capability based information system ${ }^{[1]}$.

\section{The Proposal and Development Prospect of Integrated Training Mode Under Information Condition}

\subsection{The Proposal of Integrated Training Mode}

In 2006 the PLA military training meeting clearly proposed to improve the integrated joint operation ability as the goal, and actively promote the transformation from mechanization under conditions of military training to conditions of informationization; 2007 focused on training in complex electromagnetic environment, explore the questions of training conditions under the condition of information; 2008 focused on the reform of training content, initially constructed military training content system under the condition of information; 2009 focused on cross base training, explored base training, network training, simulation training and other new training methods.2010 years, gradually formed a consensus: the target of training under the condition of informatization is to form and improve the combat capability based on information system; under the condition of information training, the essence is the realization of the "two a go". Since then, from the training of combat elements integration, to combat unit synthesis training pilot, gradually promote the training mode innovation under the condition of informationization, the development of a new model is more in line with the current actual training --based on the integration of information system, the system is composed of operational elements integrated training, combat unit synthesis training, combat training and system integration ${ }^{[2]}$

\subsection{Integrated Training Exploration}

In carrying out the integrated training pilot and promotion process, all units with their own reality, and actively explore the way of integrated training organization and implementation, has accumulated a lot of experience and lessons and lay a solid foundation for the integrated training organization and operation specification. 


\subsubsection{Air force integrated training practice}

The air force from the red and blue maneuvers to explore the ways of combat system construction, system integration confrontation, comprehensive effect evaluation system against the training method. In the fight marshalling, grouping the troops of training system according to the operational requirements, forming two basic combat groups with complete elements and power equivalence; in preparation for combat drills, the power system of the troops concentrated to the same region, in accordance with the system of resistance training program and method to drill repeatedly, Verification methods and action plans for the base stationed in the implementation of the system to lay a solid foundation for resistance training; in the way of fight, actively carrying out intelligence reconnaissance confrontation, command confrontation, air-to-air confrontation, air ground confrontation, electronic warfare, integrated security confrontation and so on; In the evaluation of combat effectiveness, the use of information monitoring system for real-time transmission of data, real-time determination of the results of the confrontation, a comprehensive analysis of gains and losses of operational, and focusing on the exchange of experiences and lessons learned, effectively improve the quality of training and combat capability.

\subsubsection{Summary of headquarters integrated training}

The integrated training mainly includes the integration of operational factors, the combat unit synthesis training and the combat system integration training. On operational factor integrated training, pilot units focus on communications security, reconnaissance, command and control, firepower, protection equipment, such training content of five elements; combat unit synthesis training, pilot troops explored a way of grouping power fusion, information oriented training content, training and outreach in the set of steps based on evaluation ability, form the basic path of the army combat unit synthesis training; combat system integration training is an important step to eventually form the combat capability of the system, is the overall fusion and the dynamic test of the whole elements and system on the basis of two kinds of training concerned before. Through the trial and exploration, the relevant laws and regulations are issued by the headquarters, clearing the relevant concepts, standardizing the content standards, improving the operating rules and implementing measures from the top to guide and regulate the integrated training.

\subsection{Development Direction of Integrated Training}

The development of integrated training needs two stages: the first stage is the training under the conditions that information weapon equipment and the system of information is not perfect, the corresponding operation is under the condition of information warfare; the second stage is the training that information weapon equipment and the system of information is very complete, also is the integration the training, the corresponding operation is information warfare.

\subsubsection{Integrated training will coexist with traditional training mode for a long time}

Because of the low level of information construction of weaponry and equipment, At present, the research of integrated training is based on the existing information system and information weapon equipment, On the basis of mechanization and semi mechanized weapon equipment The training content and form have the characteristics of old and new coexistence, complex development and gradual change, and the integrated training will coexist with traditional training for a long time

\subsubsection{Integrated training to the direction of integrated training}

The highest stage of combat system is integrated operations, integrated training is the highest stage of integrated training. Integrated training is the inevitable choice under the condition of information continued to promote the transformation and development of military training mode, is the effective way of generating combat capability based on information system under the condition of informationization, integration training will eventually to the joint training mode of future information warfare integration direction.

\section{Integrated Training System and Typical Characteristics of US Army Digital Force}

Integrated training is a new training mode under the informationization conditions. Although the US Army does not put forward the concept of integrated training, the system training based on the networked information system is the important training form which is experimenting and practicing. 
US Army weapons and equipment have high degree of information technology, and the information systems are more developed. The combat practice experience is also more abundant. Based on the information system training system, the organization is more mature, and there are many lessons learned to learn from.

\subsection{The Integrated Training Conception and System of US Army Digital Force}

Digital force is a more complete information system based on the combat system, and the training itself is the advanced stage of integrated training. In order to improve the training of digital forces, the US Army has developed three plans, namely, '21st Century Soldier', '21st Century Warrior' and '21st Century Warrior Network' planning ${ }^{[3]}$. The integrated training of the US Army Digital Force is mainly carried out with the non-digital forces against the exercise and the "Advanced Combat Test", the training system consisting of five levels ${ }^{[4]}$ :

\subsection{Typical Characteristics of Integrated Training of US Army Digital Force}

To improve the training effect, the US Army has prepared training materials based on three training programs and tactical technical procedures adapted to the digital battlefield environment requirements. From 1992, many trials have been able to see that the US Army Digital Force integrated training mainly has the following characteristics:

3.2.1 Highlight the collaborative training between the various systems and the arms and services

Collaborative training Digital forces are multi-component synthetic forces, with a variety of digital systems. US Army focus on collaborative training, so that all the weapons of the weapons system and the combat unit to form a whole, playing an efficiently role in all aspects quickly ${ }^{[5]}$.

\subsubsection{Extensive simulation based on virtual reality technology}

The US military purchase and use simulation training equipment, developing new simulation software. The use of simulation training means can reduce the loss of weapons and equipment, save money, improve operational capacity, reduce training time, but also improve the training effect.

\subsubsection{Strengthen the targeted training of information acquisition and utilization ability}

In the usual training and exercises, the US military strengthen the ability to obtain information targeted training. Tests show that the new digital equipment to the following units of the commanders and soldiers won an unprecedented understanding of the battlefield situation, and the ability to connect the different combat platforms to form a unified overall strike force.

\section{The Enlightenment of Integrated Training of US Army Digital Force}

The US Army's integrated training is at the forefront of the world, and other countries are still exploring and developing. Integrated training is a new training mode under the informationization conditions. To carry out integrated training not only to reform the training system itself, but also the development of information technology weapons and equipment, building a training standard system, creating training and security conditions, in order to truly make integrated training to implement and play a benefit.

4.1 Vigorously Strengthen the Construction of Weapons and Equipment Information for The Integrated Training to Provide the Basic Platform

The material basis of the integrated training is the information system and information weapons and equipment. Informatization of weapons and equipment is the basis for the implementation of integrated construction and prerequisite. Only the weapons and equipment to achieve the information in order to form a combat system through the information system for the integrated training to lay the foundation platform. Weapons and equipment information construction is mainly on the weapons and equipment for information transformation, and the development of new combat weapons and equipment, to build a new information technology weapons and equipment system.

4.2 Accelerate the Integrated Construction of Information Systems to Provide Network Support for Integrated Training

Information system integrated construction is to improve the overall combat capability and the optimal allocation of information resources, the arms and arms information systems and information weapons and equipment integrated into an integrated combat system. Digital integration of weapons and equipment, first of all in the factory integration design to ensure that all types of combat 
equipment and equipment to the integration of natural integration. The second step in comprehensive integration is to conduct a pilot demonstration in the army, and gradually build a complete weapons and equipment system.

\subsection{Focus on the Cyber-Centric Warfare Advanced Training Concept, to Provide Theoretical Basis for Integrated Training}

The US military network warfare believes that the future war military organization will be in the direction of the development of the system, decentralized deployment of combat forces, weapons platforms, sensors and decision-making agencies through the network to achieve integration, sharing battlefield situation and situation judgments, and thus the formation of information advantages and finally the combat advantage. This new understanding of the way of fighting provide a basic theoretical basis for the design of integrated training system and institutional mechanisms .

\section{Conclusion}

The integrated training based on information system is still in the initial stage of development, facing many difficulties. The US military forces' research results are generally recognized with a high degree of information, construction, training started early and experienced, providing new ideas for follow-up research and explore to the integrated training. We should learn from the good practices of the US military and make full use of the existing achievements to learn lessons, and combine our own reality to open up ideas and explore the integrated training research consisting with the actual training of troops.

\section{References}

[1]. Qian Siwen, Wang Jishan. Theory and practice of integrated training of operational elements [M]. Beijing: National Defense University Press, 2014,56.

[2]. Deng Honghuai, Zhang Hui. Research on the basic problems of integrated training [M]. Beijing: Hai Chao Press, 2014,p.28.

[3]. Wang Baocun. Review of the United States Army Digital troops training [J]. Foreign Military Studies, 1999 (7),p.3-5.

[4]. U.S.Army Research Institute. The Train, Retention, and Assessment of Digital Skills: A Review and Integration of the Literature [R]. Nov, 2006,3-6.

[5]. Research on the development of the United States Army digital army information system [R]. World Military Electronics Research, 2012 (1),1-12. 